\title{
An Overview of Urban Land Expansion in China in the 1990s Based on Remote Sensing and GIS Technologies
}

\author{
LIU Jiyuan*, and DENG Xiangzheng** \\ *Institute of Geographical Sciences and Natural Resources Research \\ Chinese Academy of Sciences, Beijing, 100101, P.R.China, \\ **Center for Chinese Agricultural Policy, Chinese Academy of Sciences, Beijing, 100101, P. R. China
}

\begin{abstract}
Urban land expansion is the closest representation of urbanization in spatial dimension, and is one of the most important factors affecting land-use/cover change on a regional scale. China has experienced rapid urban growth, which can be monitored by the Landsat TM digital images. This paper measures urban land expansion in China using the high resolution Landsat TM digital images in three periods, 1989/1990, 1995/1996 and 1999/2000, and identifies four types of urban land expansion, namely neighborhood, axis-based, pole-based and multi-nucleus expansion which coexisted in the 1990s. The urban land expansion in China totals 817 thousand hectares, among which the expansion during the first half (1990-1995) is more than four times that of the latter half. This paper identifies the main factors contributing to the formation of the four types of urban expansion patterns based on cases studies of Beijing, Guangzhou, Shanghai and Zibo, and gives a detailed account of the driving forces of urban land expansion in the 1990s.
\end{abstract}

Key words: urban land expansion, spatial-temporal pattern, China, the 1990s, Landsat TM digital image

\section{Introduction}

Urbanization is a conversion process from traditional agricultural society to modern urban society, with essential change of socioeconomic structure (Liu 1996). Urban land expansion is the most closest representation of urbanization in spatial dimension, and is one of the most important factors affecting land-use/ cover change on the regional scale. China has experienced rapid urban growth since its economic reforms. Especially at the end of the 1980 s and the beginning of the 1990s, there was what was called in China "great mass fever" for real estate development and establishment of Development Zones (Liu 2002).

During the accelerating period of urbanization, urban land expansion in China will continue. In the developed countries, urban land growth has resulted in many serious problems, such as arable land loss, water area decrease, environmental degradation, congestion, and air pollution (Deakin 1989; Ewing 1994). In this sense, the study on the spatial-temporal patterns of urban land expansion in China will not only promote the theoretical studies of urban affairs, but also put forward specific suggestions to the governments or organizations concerned to guide urban expansion rationally, to avoid the above-mentioned problems that existed in the western countries. Yet, the patterns and dynamic mechanisms of urban land expansion in China are still only poorly documented.

\section{Data Source and Processing Framework}

Satellite remote sensing, in conjunction with geographic information systems (GIS), has been widely applied and been recognized as a powerful and effective tool in detecting land use and land cover change (Ehlers et al. 1990; Meaille and Wald 1990; Treitz et al. 1992; Westmoreland and Stow 1992; Harris and Ventura 1995; Yeh and Li 1996, 1997, 1999). Satellite remote sensing provides cost-effective multi-spectral and multi-temporal data, and turns them into information valuable for understanding and 
monitoring urban land expansion and for building land use and land cover data sets. GIS technology provides a flexible environment for storing, analyzing, and displaying digital data necessary for change detection and database development.

Our primary data source is Landsat Thematic Mapper (TM) images for three years: 1989/ $1990,1995 / 1996$ and 1999/2000. Only bands 2 , 4 and 5 are used in this study because of their sensitivities to land use changes. All information related to the land use changes were extracted from these TM images except that some scenes of CBERS-1 (China-Brazil Earth Resource Satellite 1) images of 2000 were used to mosaic the missing data for some particular areas. Each Landsat image was enhanced using linear contrast stretching and histogram equalization to improve the image to help identify ground control points in rectification (Yan and Mikami 2002). The three dates of images were rectified to a common ALBERS coordinate system based on $1: 100,000$ scale topographic maps.

Post-classification comparison and multi-date composite image change detection are the two most commonly used methods in the change detection (Jensen 1996). In this study, an efficient classification system (Table 1) was designed and an effective research team was organized to work on remotely sensed data through computer-aided interactive interpretation for guaranteeing classification consistency and accuracy (Liu 1996).

After image geometric corrected and georeferenced, the average location error is less than 50 meters (about 2 pixels). The out-door survey and random sample check (covering line survey of 70,000 kilometers and 13,300 patches) testified the average interpretation accuracy for land-use was over $92.9 \%$.

Supported by the $1 \mathrm{~km}$ GRID global database, IGBP, IHDP and other international research organizations have implemented a series of researches including land cover dynamics, mechanism and global and regional models (Turner et al. 1995). The framework of $1 \mathrm{~km}$ GRID dataset, an efficient and effective data fusion method, is also used in this study. Generation of the $1 \mathrm{~km}$ GRID percentage data was processed in ESRI Arc/Info 8.02 software environment and could be described as follows: firstly, we gained land use map (1990, 1995 and 2000 , at scale of $1: 100,000)$ and land-use change map (1990-1995, 1995-2000, 19902000) based on the interpretation of Landsat TM images and generated a $1 \mathrm{~km}$ vector data geo-referenced to China boundary at scale of 1 : 10,000; secondly, we intersected the land-use/ land-use change patches map with $1 \mathrm{~km}$ vector data; thirdly, under TABLE model, statistical process of each kind of land-use/land-cover change area was grouped by $1 \mathrm{~km}$ vector cell ID; finally, we converted the vector data into grid format data with area percentage information of all land-use/land-use change types which we are interested.

On the basis of the $1 \mathrm{~km}$ GRID percentage dataset of each kind of land use category, we programmed in the ARC/INFO environment and generalized a certain but single expansion for each kind of land-use category at scale of 1

Table 1. Land-use classification system

\begin{tabular}{|c|c|}
\hline Land use categories & Description \\
\hline Cultivated land & Lands for agriculture \\
\hline Forestry area & Areas growing trees including arbor, shrub, bamboo and lands for forestry use \\
\hline Grassland & $\begin{array}{l}\text { Lands covered by herbaceous plant with coverage greater than } 5 \% \text {, including } \\
\text { shrub-grass for pasture and the woods with cover canopies less than } 10 \% \text {. }\end{array}$ \\
\hline Water area & $\begin{array}{l}\text { Areas covered by natural water bodies or lands with facilities for irrigation and } \\
\text { water reservation }\end{array}$ \\
\hline Built-up area & $\begin{array}{l}\text { Lands used for urban and rural settlements and factories and transportation } \\
\text { facilities }\end{array}$ \\
\hline Unused & Lands that are not put into practical use or difficult to use \\
\hline
\end{tabular}

Built-up area was classified into three categories: urban land, rural settlements and other built-up area, as urban land was a special focus, of this study. 


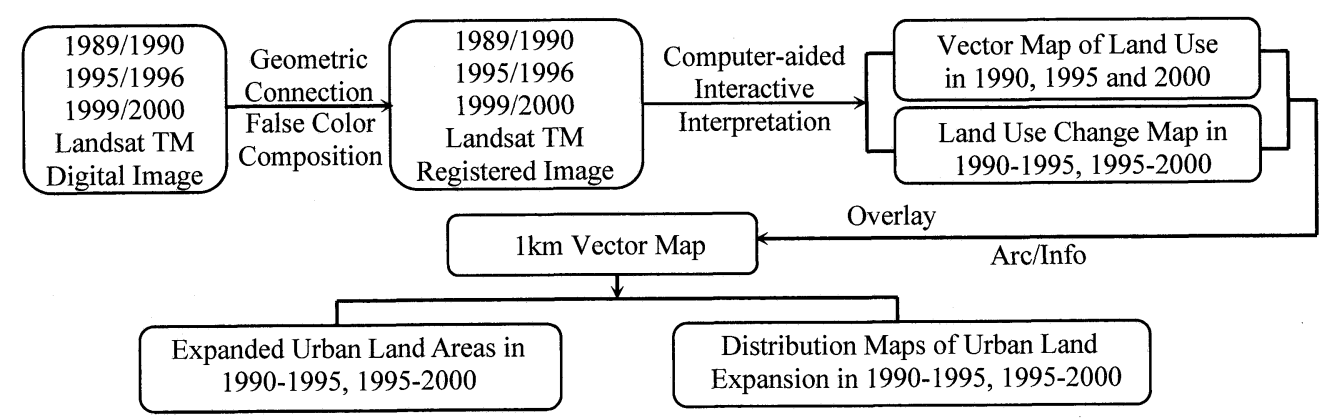

Figure 1. The framework of data handling.

$\mathrm{km}$ (Figure 1), which lay the foundation for the further analysis of urban land expansion. Figure 2 shows the distribution characteristics of urban land expansion of China in the 1990s.

Based on the interpretation of the Landsat TM images, we made a summary of urban land expansion in China in the 1990s. Since the 19th century, many researchers have discussed patterns of urban land expansion (Peiser 1989; Ewing 1994; Bourne 1996; Meaille and Wald 1990). These researchers, having different backgrounds, carried out studies on urban spatial expansion from different viewpoints, and attained many well-known patterns that could be classified into four types, i.e. neighborhood expansion pattern, axis-based expansion pattern, pole-based expansion pattern and multinucleus expansion pattern. Supported by our primary study, we found that these four types of urban land expansion patterns all existed in China. After a summary of urban land expansion in China in the 1990s, we will make a more detailed analysis of urban land expansion patterns by studying several typical cities.

\section{The Quantitative and Structural Change of Urban Land Expansion}

Based on the interpretation of Landsat TM images, the total areas of urban land areas amounted up to 817 thousand hectares in 1990 , and the expanded areas of urban land during 1990-1995 and 1995-2000 totaled 660 and 157 thousand hectares.

Figure 3 illustrates urban land use statistics and their growth characteristics for the three time scales 1990-1995, 1995-2000 and 19902000. The expansion tendency of urban land is very obvious, especially during the early 5 years, which generally determined the basic pattern of the urban land expansion.

In the 1990s, urban land expansion in China totaled 817 thousand hectares, of which the expansion during the former 5 years (19901995) was 4.2 times that of the latter 5 years (1995-2000). During the former 5 years, influenced by the upsurge of real estate development, the central and the eastern areas, especially the eastern coastal areas, which included economically developed provinces, saw conspicuous urban land expansion. In the latter 5 years, some cultivated land protection policies restrained irrational development of real estate to a certain degree, which in a sense controlled urban land expansion in some areas. At the same time, the implementation of the West Development Policy fueled the urban land expansion in western areas, then on the whole the ladder-like tendency of urban land expansion comes into being from eastern to western area.

During the urban land expansion process, non-urban land is converted to urban land according to its character. Land property and its surrounding environment determine the conversion type. Table 2 summarizes the conversion areas from other land use categories to urban land.

Table 2 shows the obvious expansion of urban land and a large share of it comes from the conversion of cultivated land. Areas of conversion from cultivated land to urban land during the former 5 years are more than 4 times that of the latter 5 years. The converted areas from forestry area during the former 5 years are also over 5 times that of the latter 5 years. Conversion areas from grassland to urban land in 1990-1995 are a little larger than those con- 

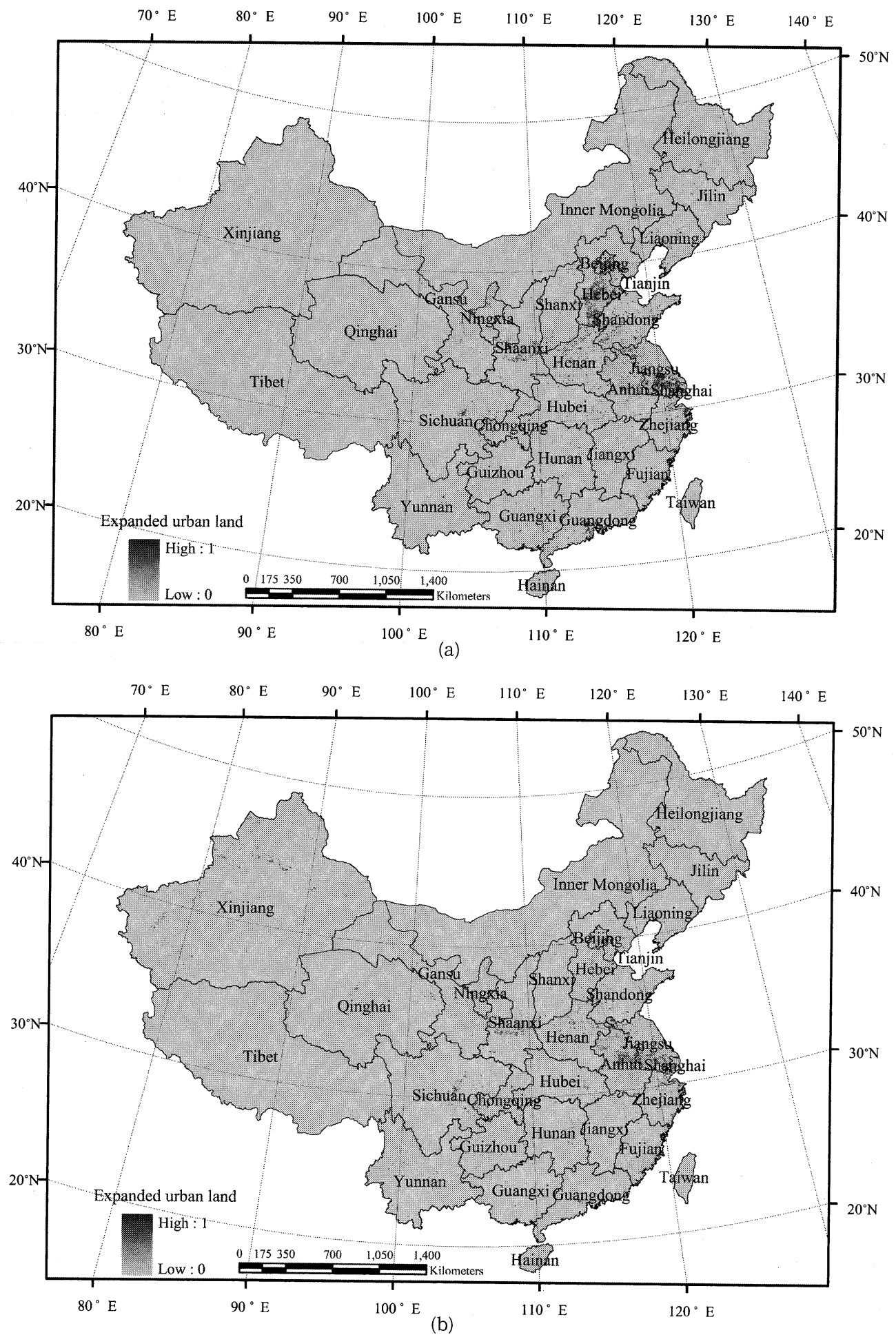

Figure 2. Distribution maps of urban land expansion of China in the 1990s.

(a) and (b) show the distribution characteristics of urban land expansion during 1990-1995 and 1995-2000 respectively; area rate of expanded urban land to a $1 \mathrm{~km} \times 1 \mathrm{~km}$ GRID is calculated to identify the urban land expansion illustrated by a stretched range [0 1] represented in the Legend. 


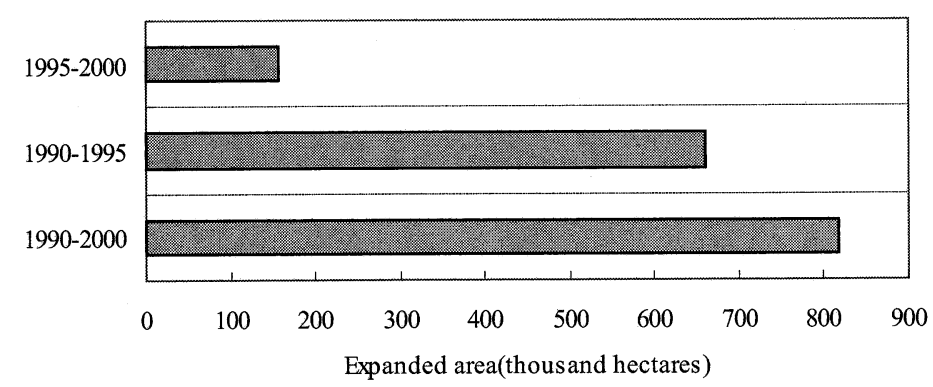

Figure 3. Expanded areas of urban land of China in the 1990s.

Table 2. Quantitative structures of land-use conversions from non-urban land to urban land in China in the 1990s (thousand hectares)

\begin{tabular}{ccccccc}
\hline $\begin{array}{c}\text { Time } \\
\text { series }\end{array}$ & $\begin{array}{c}\text { Cultivated } \\
\text { land }\end{array}$ & $\begin{array}{c}\text { Forestry } \\
\text { area }\end{array}$ & Grassland & Water area & $\begin{array}{c}\text { Rural } \\
\text { settlement }\end{array}$ & $\begin{array}{c}\text { Unused } \\
\text { land }\end{array}$ \\
\hline $1990-1995$ & 527 & 32 & 11 & 9 & 93 & 1 \\
$1995-2000$ & 129 & 6 & 10 & 3 & 4 & 4 \\
$1990-2000$ & 656 & 38 & 21 & 12 & 97 & 5 \\
\hline
\end{tabular}

verted in 1995-2000. The conversion areas of water area to urban land of the former 5 years are 3 times that of the latter 5 years. The share of conversion from rural settlement to urban land during the fast 5 years is amazingly larger than that of the latter 5 years, over 23 times that of 1995-2000. The conversions from unused land to urban land in the latter 5 years are 4 times that of the former years that shows a more and more increasing treads for unused land loss due to urbanization in China.

\section{Spatio-temporal Patterns of Urban Land Expansion}

China's urban expansion in the 1990s took place in two different phases, the urban land expansion during the first 5 years had a high speed and was concentrated in Jing-Jin-Tang areas, the Yangtse River Delta, the Pearl River Delta, North China Plain, and the coastal area of southeast China. Multi-nucleus urban land expansion could be found. The expanding rate of the latter 5 years slowed down in the Pearl River Delta and the Yangtse River Delta, and the foci of urban land expansion during this period shifted to Sichuan Basin and North China Plain. The neighborhood expansion pattern, axial expansion pattern and pole-based expansion could easily be found, but the expansion rate was comparatively small.

\section{Spatial pattern of urban land expansion in 1990-1995}

In the early 1990s, urban land expansion was mainly concentrated in Hainan province, JingJin-Tang, the Yangtse River Delta, and the Pearl River Delta (Figure 2). The expansion rate in Hainan was the highest, with a rate of $117 \%$, and the newly expanded areas totaled 9.7 thousand hectares. Their expansion patterns included neighborhood expansion pattern and pole-based pattern. Haikou city's expansion pattern belongs to neighborhood expansion type and its adjacent areas expanded with pole-based expansion type. Hainan province came into being in 1988 and became the largest special economic zone. The comparatively looser policy environment helped the fast development of real estate, and the urban construction promoted urban land expansion.

The Pearl River Delta is adjacent to Hong Kong and Macao, and foreign capital contributed to the development of the export economy as well as the urban construction. Urbanization progressed very fast, and multi-nucleus expansion, neighborhood expansion and axis-based expansion was predominant. The Yangtze River Delta is among the developed areas in China, so the village and township enterprises prospered and the regional economy developed 
at high speed, promoting the expansion of urban land, at a rate of $30 \%$. The multi-nucleus expansion pattern is predominant. Promoted by huge urban land expansion in Beijing, a conspicuous neighborhood expansion, the urban land expansion in Jing-Jin-Tang areas expanded at a rate of $110 \%$; the expanded area account for $14 \%$ of China's expanded urban land in the early 1990s.

In the early 1990s, urban land expansion in the coastal and North China Plain areas accounted for $75 \%$ of that in the whole country, and the other areas accounted for 25\%. Among densely distributed areas of towns, the Pearl River Delta, the Yangtze River Delta and the Jing-Jin-Tang areas had a high speed of urban land expansion, followed by areas such as the Zhongyuan city zone, Taiyuan city zone, Ningxia Plain, Shandong Peninsula, Nanchang city zone, and Sichuan Basin. And comparatively speaking, Fuxia city zone, Wuhan city zone, Hanzhong city zone and Liaozhong urban group had a lower speed of urban land expansion. The situation above was mainly influenced and determined by the opening policies in coastal areas in China. Rapidly emerging economic and technological developing areas and accelerated development of real estate industry in coastal areas caused an increasing demand for urban land and therefore had a high urban land expansion speed. On the other hand, economic development in central-western China and the northeast China was relatively slow, so their urban land expansion waited to be developed.

\section{Spatial pattern of urban land expansion in 1995-2000}

The urban land expansion speed slowed down greatly and urban land area had a mere increase of $4 \%$ in the late $1990 \mathrm{~s}$. The whole country, except for the Hetao plain and Tibet plateau, where the urban land expansion speed was increased, all other areas had a lower urban land expansion speed than that in the early 5 years of 1990s.

In the latter half of the 1990s, areas that had a high urban land expansion speed were as follows: Tibet plateau (pole-based expansion), Sichuan basin (axis-based expansion), Yungui
Plateau (pole- and axis-based expansion) and Hanzhong Basin (pole- and axis-based expansion), of which the urban land expansion rates were $76 \%, 31 \%, 16 \%$, and $12 \%$, respectively. Due to the increasing investments of governments in Tibet and Qinghai Province, the urban land expansion and development speed in the Tibet Plateau was higher than that in the first 5 years of the 1990s.

There was an urban land expansion of a comparatively low speed in the Ningxia Plain, the loess plateau, the southeast coastal densely distributed areas of towns, the southwest city zone and the Liaozhong city zone, in which the urban extension rate ranged between $3.9 \%$ and $6 \%$. The Zhongyuan city zone, the North China city zone, the Fuxia city zone, the Xiangzhong city zone, the Wuhan city zone, the central China city zone, the Taiyuan Basin, the Shandong Peninsula, the east Part of northeast China and the Inner Mongolia plateau had a varying urban land expansion rate from $1 \%$ to $3.1 \%$. The Changchun-Haerbin-Dalian city zone and the Hetao Plain had an urban land expansion rate lower than $1 \%$.

Based on the data analysis we can find that during the latter 5 years of the 1990s, the urban land expansion area in the coastal and North China Plain areas accounted for $23 \%$ of the whole country, and the other areas accounted for $77 \%$. The central and western parts of China have become the main areas of urban land expansion.

\section{Case Studies of Urban Land Expansion of China in the 1990s}

\section{Urban land expansion in Beijing}

Beijing is the national political capital with a total population of more than 12 million. In the 1990s, the urban land in Beijing increased 35.8 thousand hectares, mainly transformed from cultivated land. From the space view, the urban land expanded continuously and concentrically in all directions. The expansion to the southwestward was outstanding, about $10 \mathrm{~km}$ in distance, while the spread northwestward was a minimal amount $3-4 \mathrm{~km}$, other expanding directions expanded at a moderate level of 5-6 km (Figure 4). Given the advantageous 


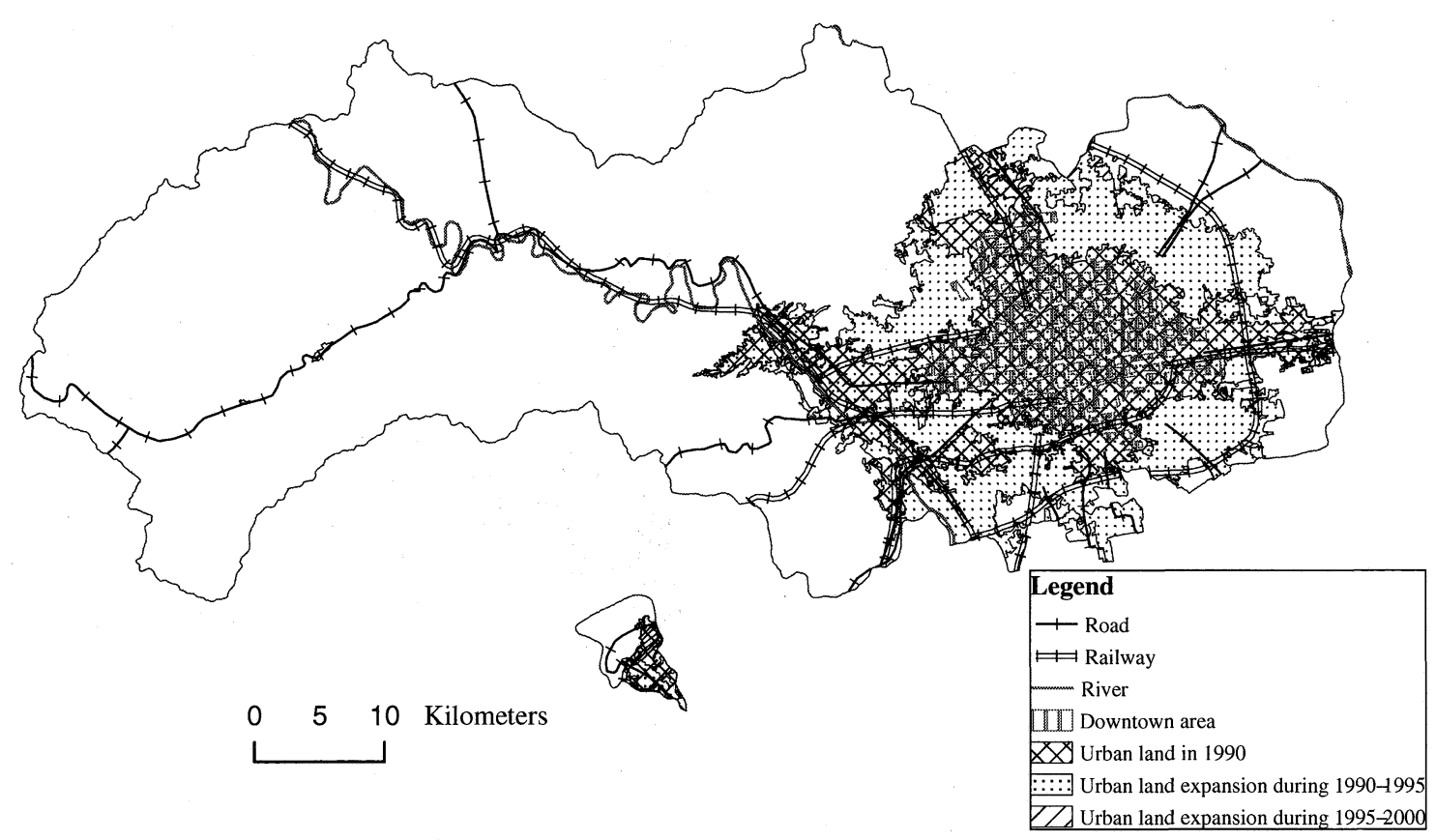

Figure 4. Urban land expansion of Beijing in the 1990s.

condition, the eastern and southern plains with highly developed economy and transportation are propitious to urban land expansion; the construction of Jing-Jin-Tang highway will accelerate the expansion in this direction.

The growth of non-agricultural population and total population, together with the development of the tertiary industry, has become the main driving force of urban land expansion in Beijing (Liu 2002). The relationship of urban land expansion and some selected social and economic indicators show that there exist significant positive correlation between urban land expansion and the growth of gross output value, total population, non-agricultural population, with a correlation coefficient above 0.8 (Table 3), which in some sense, proves that the urban land expansion of Beijing is mainly driven by the development of society and economy, apart from the physical conditions which have controlled and affected the fundamental patterns of urban land expansion in the city. Besides, government policy also played a key role in the course of urban land expansion in Beijing during the 1990s, which has resulted in neighborhood expansion.

\section{Urban land expansions in Guangzhou}

Guangzhou, the provincial capital of Guangdong on both banks of the Zhujiang River, is situated in the north of the Zhujiang Delta, at the confluence of the Xijiang, Beijiang, and Dongjiang rivers and the junction of the Beijing-Sanshui railways. The urban land of Guangzhou increased about 10.8 thousand hectares in the 1990s, among which, 5.4 thousand hectares came from the conversion of cultivated land. Before the economic reform and "open-door" policy were brought into effect, the urban land of Guangzhou was basically located between the Yuexiu hill and the north sea-route of the Pearl River. Stimulated by economic development, the urban land expansion of Guangzhou showed a great change from 1993. The urban land began to expand eastward along the north bank of the north sea-route of the Pearl River, the old suburb changed to a more modernized urban area very soon with the development of the Wuyangtun and Tianhe zone. After the construction of Zhongshan Road and Huangpu Road, the old districts of Guangzhou, the Tianhe new zone and old Huangpu district were linked together. Along 
Table 3. A summary of the partial correlation coefficients between the expanded urban land and some selected social and economic indicators for Beijing, Shanghai, Guangzhou, and Zibo

\begin{tabular}{|c|c|c|c|c|c|}
\hline Indicators & Unit & Beijing & Shanghai & Guangzhou & Zibo \\
\hline \multirow[t]{2}{*}{ TPOP } & 10 thousand person & 0.882 & 0.863 & 0.679 & 0.753 \\
\hline & & $\mathrm{P}=0.011$ & $\mathrm{P}=0.002$ & $\mathrm{P}=0.000$ & $\mathrm{P}=0.004$ \\
\hline \multirow[t]{2}{*}{ NAP } & 10 thousand person & 0.801 & 0.796 & 0.576 & 0.69 \\
\hline & & $P=0.000$ & $\mathrm{P}=0.001$ & $\mathrm{P}=0.001$ & $\mathrm{P}=0.000$ \\
\hline \multirow[t]{2}{*}{ POPI } & $\%$ & -0.569 & -0.715 & -0.476 & -0.568 \\
\hline & & $P=0.000$ & $\mathrm{P}=0.001$ & $\mathrm{P}=0.001$ & $\mathrm{P}=0.000$ \\
\hline \multirow[t]{2}{*}{ POSI } & $\%$ & 0.678 & 0.809 & 0.571 & 0.792 \\
\hline & & $P=0.000$ & $P=0.006$ & $\mathrm{P}=0.000$ & $P=0.000$ \\
\hline \multirow[t]{2}{*}{ POTI } & $\%$ & 0.411 & 0.739 & 0.611 & 0.514 \\
\hline & & $\mathrm{P}=0.001$ & $\mathrm{P}=0.021$ & $\mathrm{P}=0.000$ & $\mathrm{P}=0.000$ \\
\hline \multirow[t]{2}{*}{ TGDP } & a hundred million yuan & 0.886 & 0.729 & 0.386 & 0.892 \\
\hline & & $P=0.000$ & $\mathrm{P}=0.000$ & $\mathrm{P}=0.000$ & $\mathrm{P}=0.000$ \\
\hline \multirow[t]{2}{*}{ TIFA } & 10 thousand yuan & 0.467 & 0.608 & 0.497 & 0.9 \\
\hline & & $P=0.021$ & $\mathrm{P}=0.002$ & $P=0.001$ & $\mathrm{P}=0.000$ \\
\hline \multirow[t]{2}{*}{ FI } & 10 thousand USD & 0.662 & 0.705 & 0.823 & 0.537 \\
\hline & & $P=0.000$ & $P=0.001$ & $\mathrm{P}=0.000$ & $\mathrm{P}=0.002$ \\
\hline
\end{tabular}

TPOP-Total population; NAP-non-agricultural population; POPI-percentage of the output of primary industries; POSI-percentage of the output of secondary industries; POTI-percentage of the output of tertiary industries; TGDP-total gross domestic products; TIFA-Total investment in fixed assets; FI-foreign investment. P means the significant level at 5\%. Data sources: Statistical yearbook of cities in China, 1990-2000. Beijing: China Statistics Press.

the two main roads, the cultivated land or other land use types were rapidly developed into urban areas. Approved by the Guangzhou general city planning, the urban land of Guangzhou mainly expanded eastward, southward and southeastward after the middle of the 1990s. By 2000, Guangzhou has shaped an obvious strip or belt urban form (Figure 5).

The convenient river traffic network lay the foundation for the urban land use expansion of Guangzhou, resulting in, the axis expansion of urban land use. Table 3 also shows there exists significant positive correlation between urban land expansion and the selected social and economic indicators, among which the foreign investment is predominant driver forces for the urban land use expansion, with a correlation coefficient above 0.8 in 1990-1995 and 19952000 .

\section{Urban land expansions in Shanghai}

Shanghai, one of the largest cities in China and one of the four centrally administered municipalities, is situated along the middle of the mainland coastline at the Changjiang River outlet to the East China Sea. It is among the most rapid developing cities worldwide. In the
1990 s, the average annual growth rate of the total population and GDP of the whole Shanghai Municipality Area is $0.3 \%$ and $11 \%$ respectively. With the introduction of economic liberalization and urban land market, the dynamic forces of urban transformation in Shanghai have shifted from the formerly rigid state control to interplay between the state and the market (Han 2000; Liu 2002; Yan, Kubo, and Ishimaru 2002)

With the speed up of the Pudong infrastructure construction and the expansion of foreign relations, business and trade development have an attractive future. The development of $\mathrm{Pu}$ dong has promoted the structural change of land use in Shanghai in the 1990s, the urban land expanded obviously, and the urban land was expanded by 17.6 thousand hectares during 1990-1995 and 0.8 thousand hectares during 1995-2000 (Figure 6).

For the urban land expansion in Shanghai in the 1990 s, mainly represented as the Pudong development, apart from the drivers of population growth, economic development and the industrial readjustment, as also can be identified in Table 3, the developing policies made by local and central governments, meeting the 


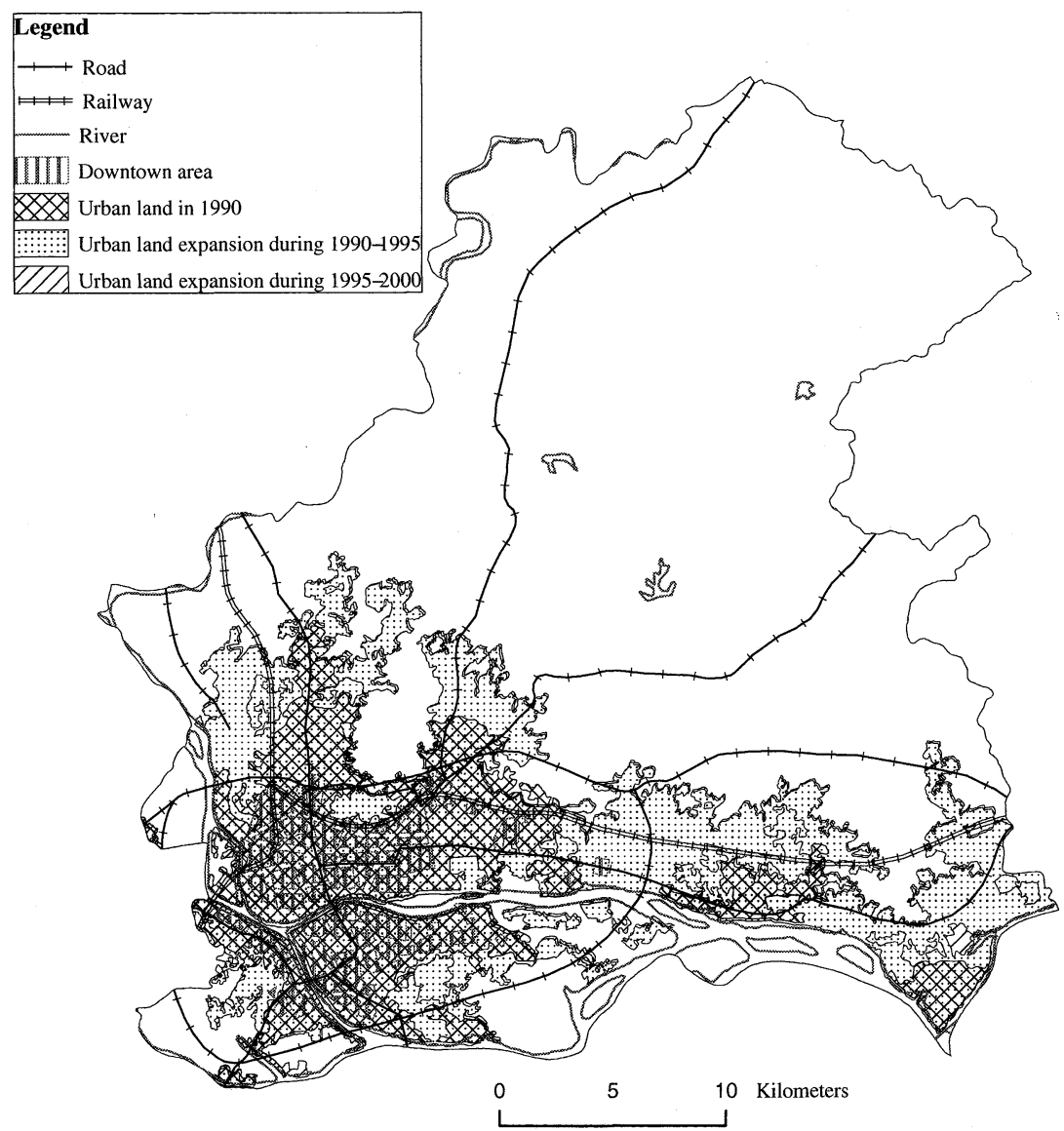

Figure 5. Urban land expansion of Guangzhou in the 1990s.

needs to reestablishment of Shanghai trade center, would rank the first for the land use change there. Pudong opening and development, launched in the beginning of the 1990s and determined by the central government, can be a breakthrough in the reestablishment of Shanghai trade center, which in some sense, led to the pole-based expansion of Shanghai in the 1990s.

\section{Urban land expansions in Zibo of Shandong Province}

Situated on the borderline of the Round-theBohai-Sea economic zone and Along-theYellow-River economic cooperation zone, Zibo, famous for its unique city layout ( $Z i b o$ mode), is an industrial city with unique characteristics in the Round-Sea Area of China. Zibo is one of the open coastal cities of the Shandong Peninsula, and has long won the reputation of the "capital of ceramics" and the "city of silk." Rich in natural resources, Zibo has so far prospected more than 50 kinds of mineral resources. Zibo is, therefore, one of the main producers of ore in Shandong Province. Ever since the implementation of China's policy of reform and opening to the world, Zibo has demonstrated great achievements in economic development. It, therefore, ranks as one of the 50 cities that have greatest tremendous comprehensive economic strength in China.

There are many different views on the formation of Zibo mode, among which, the historic reason, the development of mining industries and the scattered distribution of secondary industries, laid the foundation for Zibo mode. Based on the interpretation of Landsat TM images, it is self-evident that the urban sprawl is still developed with a multi-nucleus pattern (Figure 7). The urban land was expanded by 1.2 and 0.9 thousand hectares in 1990-1995 and 


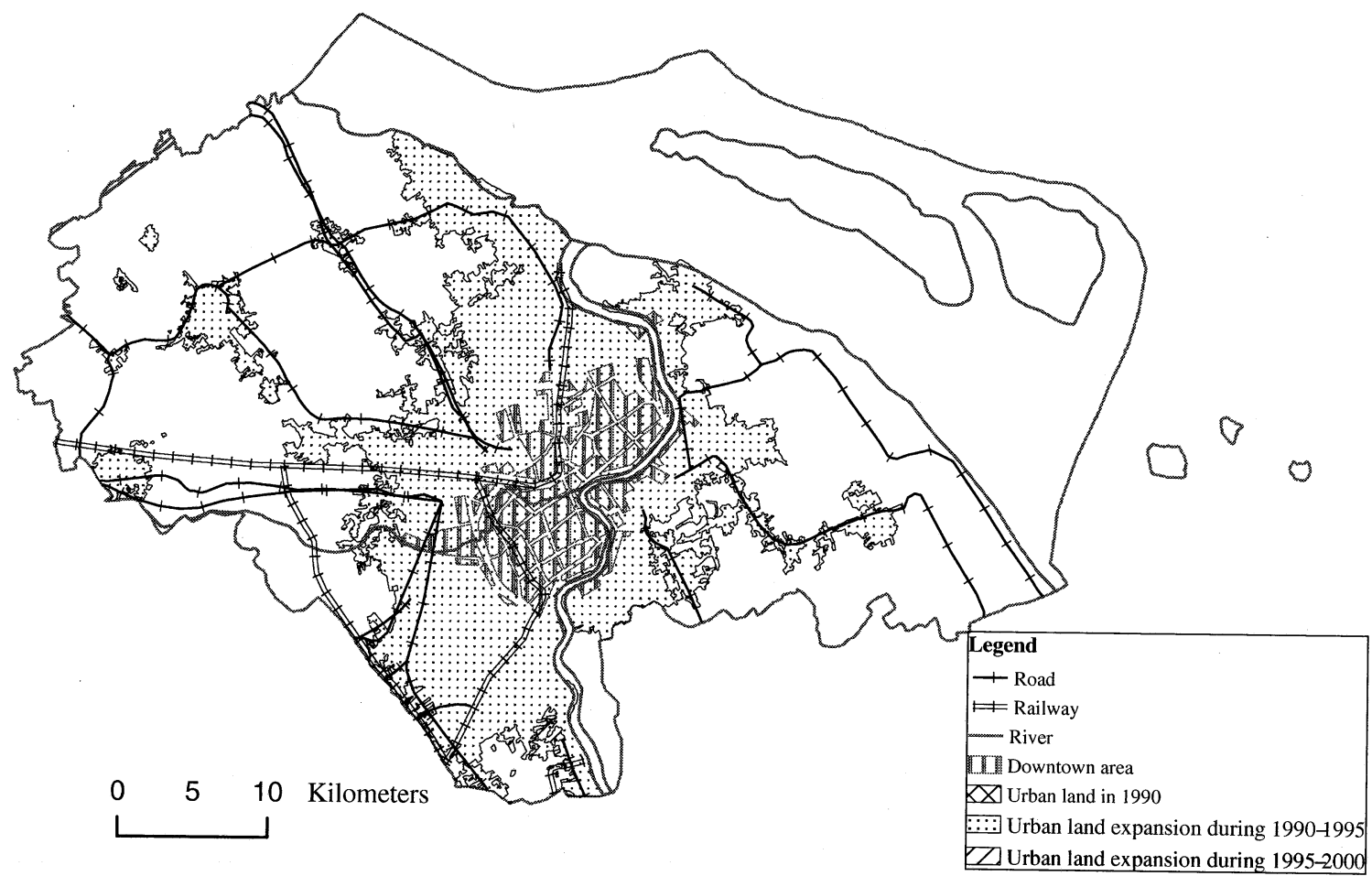

Figure 6. Urban land expansion of Shanghai in 1990s.

1995-2000, respectively. It has set its great development target at the turn of the century. There also exists a positive correlation between urban land use expansion and population growth, economic growth and increase of fixed investment (Table 3). From 1999, the gross national products have increased by $9 \%$ each year during the next 5 years, and the annual income of the citizens and the farmers increased by $5 \%$ and $8 \%$, respectively. We can imagine that with the development of economy and society, the land-use structure will change together with the urban continuous expansion, but the multi-nucleus urban land expansion will be kept for a long time.

\section{Conclusions}

Urban land expansion was very obvious in China during the 1990s because of the rapid development of society and economy. For a developing country with a low urbanization level like China, normal urbanized area growth with increasing rural-urban migration is a com- mon process of modernization. Based on monitoring of the Landsat TM digital imagines covering the whole country, the urban land expansion in China totals 817 thousand hectares, among which the former 5 years' (1990-1995) expansion is more than 4 times that of the later 5 years'. Four kinds of urban land expansion patterns, neighborhood, axis-based, pole-based and multi-nucleus co-existed in the 1990s, urban land expansion was mainly concentrated in Hainan Province, Jing-Jin-Tang, the Yangtse River Delta, and the Pearl River Delta. For Hainan province and Jing-Jin-Tang, the expansion patterns include neighborhood expansion pattern and pole-based pattern. In the Yangtze River Delta, the multi-nucleus expansion pattern is predominant but for the areas affected and controlled by the terrain and other physical conditions. For the Pearl River Delta, the multinucleus expansion, neighborhood expansion pattern and axis-based expansion are predominant.

Urban land use expansion is driven by population growth and social and economic develop- 


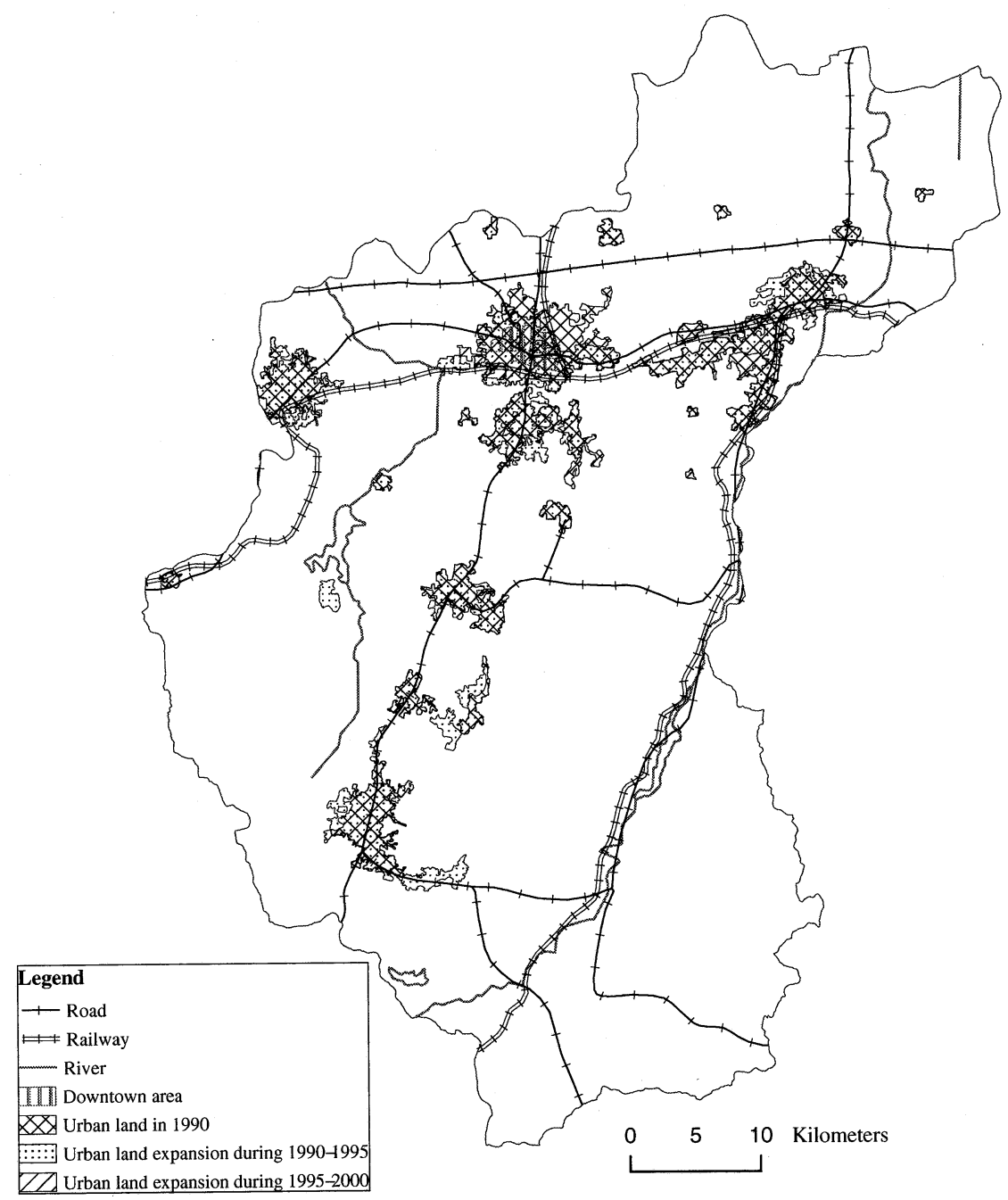

Figure 7. Urban land expansion of Zibo in the 1990s.

ment (Fishel 1982; Bourne 1996; Peiser 1989; Dipasquale and Wheaton 1996; Liu 2002). Geophysical conditions always work as the background for urban land expansion, the cities located in plains are most prone to expand with neighborhood expansion pattern; most of China's cities expanded with this pattern in the period. Cities located along shoreline, river bank or valleys are most possible to expand with axis-based expansion pattern. Urban land expansion is a dynamic process, and the cities may expand with different patterns. Apart from that, we have found that it is the combination of market forces and government's reaction (especially at the local level) to the market- place that cause urban sprawl in China. Facing the enormous loss of cultivated land in the 1990 $\mathrm{s}$, especially the first half of the 1990s, the central government put a control policy in place in recent years. In the 1990 s, with the extensive implementation of the paid fee land use system, an urban land market emerged in China. All urban development, excluding those stipulated by law to be qualified for administration allocation, is subject to purchase land use rights in an urban land market.

The overlays of the urban land use maps derived from satellite interpretation for the years 1990, 1995 and 2000 show clearly the urban land spatial patterns of Beijing, 
Guangzhou, Shanghai and Zibo. In the 1990s, original spatial patterns, neighborhood, axisbased, pole-based and multi-nucleus expansion patterns are still kept. The expansion of urban land was obvious in 1990-1995, while was slowed down in 1995-2000, similar with what had happened for the urban land expansion of the whole country in the 1990s. Apart from the unique function for each city, e.g., the policy function promoting the neighborhood expansion of Beijing, river traffic network affecting the axis-based expansion of Guangzhou, regional development planning driving the polebased expansion of Shanghai, and historic reason together with the developments of mining or other industries leading to the formation of multi-nucleus expansion in Zibo, population growth and social and economic development are the main driving forces for their urban land expansions.

In summary, this paper clearly shows that high resolution remotely sensed data can be very effective in monitoring urban development activities, which is crucial especially in a condition of rapid change such as that currently observed in China. Monitoring based on interpretation and classification of remotely sensed data allows the quantifying of the speed and spatial pattern of urban growth. In conditions where informal land transaction mechanisms abound, such as in the Chinese conditions, monitoring of land use changes can help to detect violations and enforce urban land development regulations, which, in the end, serve to rationalize the sustainable use of urban land.

\section{Acknowledgments}

This study has been sponsored by JSPS Science Fund Basic Research (S) No. 13851003 and National Natural Science Foundation of China (No. 90202002). The authors would like to express their sincere thanks to Prof. Yukio Himiyama, project leader, for his encouragement and many valuable comments on various drafts of this paper. We also deeply thank Dr. Adam Nichols for his review and comments.

(Received 29 March 2003)

(Accepted 31 July 2004)

\section{References}

Bourne, L. S. 1996. Reurbanization, uneven urban development and the debate on new urban forms. Urban Geography 17(8): 690-713.

Deakin, E. 1989. Growth control: A summary review of empirical research. Urban Land 48: 16-21.

Dipasquale, D., and Wheaton, W. 1996. Urban econom$i c s$ and real estate markets 1996 . New Jersey: Prentice Hall, Inc.

Ehlers, M., Jadkowski, M. A., Howard, R. R., and Brostuen, D. E. 1990. Application of SPOT data for regional growth analysis and local planning. Photogrammetric Engineering and Remote Sensing 56: $175-180$.

Ewing, R. 1994. Characteristics, cause, and the effects of sprawl: A literature review. Environmental and Urban Issues 21: 1-15.

Fischel, W. A. 1982. The urbanization of agricultural land: A review of the national agricultural lands study. Land Economics 58: 236-259.

Han, S. S. 2000. Shanghai between state and market in urban transformation., Urban Studies 37(11): 2091-2112.

Harris, P. M., and Ventura, S. J. 1995. The integration of geographic data with remotely sensed imagery to improve classification in an urban area. Photogrammetric Engineering and Remote Sensing 61: 993-998.

Jensen, J. R. 1996. Introductory digital image processing: A remote sensing perspective (2nd edn.). Upper Saddle River, New Jersey: Prentice Hall, Inc.

Liu, J. 1996. Macro-scale survey and dynamic study of natural resources and environment of China by remote sensing. Beijing: China Science and Technology Press.

Liu, J. Liu, M. Zhuang, D. Zhang Z. and Deng X. 2002. A Study on Spatial Pattern of Land-Use Change in China During 1995-2000. Science in China (Series D) 32(12): 1031-1040.

Liu, S. 2002. Spatial patterns and dynamic mechanisms of urban land use growth in China: case studies in Beijing and Shanghai, Interim Report of International Institute for Applied Systems Analysis. Laxenburg: IIASA

Meaille, R., and Wald, L. 1990. Using geographic information system and satellite imagery within a numerical simulation of regional urban growth. International Journal of Geographic Information Systems 4: 445-456.

Peiser, R. 1989. Density and urban sprawl. Land Economics 65: 193-204.

Treitz, P. M., Howard, P. J., and Gong, P. 1992. Application of satellite and GIS technologies for landcover and land-use mapping at the rural-urban fringe: A case study. Photogrammetric Engineering and Remote Sensing 58: 439-448.

Turner, B. L. II, Skole D., Sanderson S., Fischer G., 
Fresco L., and Leemans, R., 1995. Land-Use and Land-Cover Change (LUCC): Science/Research Plan. HDP Report No. 7. Stockholm: IGBP Secretariat.

Westmoreland, S., and Stow, D. A. 1992. Category identification of changed land-use polygons in an integrated image processing/geographic information system. Photogrammetric Engineering and Remote Sensing 58: 1593-1599.

Yan, W., and Mikami, T. 2002. Relationship between surface temperature from Landsat TM thermal images and air temperature observed on the ground, Journal of Geography 111(5), 695-710.

Yan, W., Kubo, S., and Ishimaru, N. 2002. The pro- gress of urbanization in Shanghai, Journal of $\mathrm{Ge}$ ography 111(5): 515-524.

Yeh, A. G. O., and Li, X. 1996. Urban growth management in the Pearl River delta-an integrated remote sensing and GIS approach. The ITC Journal 1: 77-85.

Yeh, A. G. O., and Li, X. 1997. An integrated remote sensing-GIS approach in the monitoring and evaluation of rapid urban growth for sustainable development in the Pearl River Delta, China. International Planning Studies 2: 193-210.

Yeh, A. G. O., and Li, X. 1999. Economic development and agricultural land loss in the Pearl River Delta, China. Habitat International 23: 373-390. 